\title{
Os Direitos Humanos e sua Eficácia Protetiva na Encruzilhada: Direito à Barbárie ou Direitos dos Oprimidos?
}

\author{
Fabio Bacila Sahd \\ Doutor em Ciências pelo Programa de Pós-Graduação Diversitas (Direitos, humanidades e outras legitimidades). \\ Professor do Colegiado de Ciências Humanas/Sociologia, da UFMA, Campus III, Bacabal (MA). fabiobacila@hotmail.com
}

RESUMO

O presente artigo propõe uma revisão bibliográfica e tece considerações críticas acerca da fundamentação teóri$\mathrm{ca}$, histórico e efetividade protetiva dos direitos humanos. Contrasta-se o avanço normativo com a vulnerabilidade concreta e negação de direitos de amplos segmentos. O texto tem início com uma apresentação sucinta dos fundamentos dos direitos humanos, e contextualiza sua consolidação no século 20. Na sequência, são expostas considerações de diferentes autores quanto à sua instituição arbitrária e difundida ineficácia. Por fim, partindo de referencial interdisciplinar, relaciona-se a fragilidade de sua vigência à própria lógica ambivalente da modernidade, que se fundamenta em uma nova lógica de poder baseada em princípios como igualdade e liberdade, mas mantém as desigualdades e opressões anteriores, como de gênero, classe e etnia. Conclui-se que os avanços normativos continuam fragilizados pela negação prática de direitos, o que pode ser compreendido a partir da própria ambiguidade da modernidade, cujos ideais igualitários são contraditados pela continuidade de diferentes formas de domínio, discriminação e hierarquias.

Palavras-chave: Direitos humanos. Modernidade. Pós-colonialismo.

HUMAN RIGHTS AND THEIR PROTECTIVE EFFICACY IN THE CROSSROAD: THE RIGHT TO BARBARISM OR THE RIGHTS OF THE OPPRESSED?

\section{ABSTRACT}

This article proposes a bibliographical review and makes critical considerations about the historic, theoretical basis and protective effectiveness of human rights. We contrast the normative advance with the concrete vulnerability and denial of rights of wide segments of human beigns. The text begins with a brief presentation of the foundations of human rights, and contextualizes its consolidation in the twentieth century. In the sequence, considerations of different authors about their arbitrary implementation and widespread inefficacy are exposed. Finally, based on a interdisciplinary referential We relate the fragility of the Human Rights to the very dichotomous logic of modernity that, if on the one hand it is based on a new logic of power based on principles like equality and freedom, on the other maintains the previous inequalities and oppressions, as of gender, class and ethnicity. We concluded that normative advances continue to be weakened by the practical negation of rights, which can be understood from the very ambiguity of modernity, whose egalitarian ideas are contradicted by the continuity of different forms of domination, discrimination and hierarchies.

Keywords: Human rights. Modernity. Post-colonialism.

SUMÁRIO

1 Introdução. 2 A consolidação dos direitos humanos, sua fundamentação e horizonte utópico. 3 Crítica à vigência dos direitos humanos na modernidade. 4 A modernidade e a barbárie. 5 Conclusão. 6 Referências.

Recebido em: 14/11/2018

Modificações requeridas em: 23/7/2019

Aceito em: 30/7/2019 


\section{Humanos e \\ Democracia}

\section{INTRODUÇÃO}

Do final do século 18 em diante, fruto de reflexões sobre a condição humana e direitos inerentes, foram feitas diversas tentativas para normatizar as relações entre os Estados e destes com seus cidadãos, como a Declaração dos Direitos do Homem e do Cidadão (1789), culminando com a Carta da Organização das Nações Unidas (ONU), em 1945, e a Declaração Universal dos Direitos Humanos (DUDH), em 1948, cujos princípios foram retomados e mais bem sistematizados em 1966 por meio de dois "pactos internacionais" (direitos civis e políticos e direitos econômicos, sociais e culturais). Além destes, após a DUDH, vários instrumentos específicos foram forjados para enfrentar situações como genocídio, discriminação racial, contra mulheres e povos indígenas e direito ao mar, meio-ambiente sustentável, paz e desenvolvimento. Consolidou-se, assim, o Direito Internacional dos Direitos Humanos (DIDH), tendo como seu centro e principal vetor de universalização a ONU, acompanhada do estabelecimento de sistemas regionais (americano, europeu, africano) e de organizações não governamentais, além das conferências mundiais, como em Teerã (1968) e Viena (1993) (GUERRA, 2011, p. 84-86, 95-96, 101).

Pari passu à secular e gradativa consolidação do $\mathrm{DIDH}$, desde os primeiros ensaios no século 18 até os tratados e conferências mais recentes, no entanto, ocorreram violações dos próprios princípios e direitos idealizados. Como veremos, há quem explique a própria codificação, ou interdito, a partir do arrependimento moral diante de atrocidades cometidas, que seriam assim necessárias (ENRIQUEZ, 2001; COMPARATO, 1999). Cabe mencionar, rapidamente, alguns casos mais alarmantes, que ilustram a tortuosa trajetória da efetivação de direitos teoricamente assegurados, problematizando discursos que enaltecem acriticamente o suposto "avanço civilizacional" representado pela consolidação e mundialização do DIDH. Lynn Hunt (2009) destaca que, pouco depois da "Declaração dos Direitos do Homem e do Cidadão" ter sido proclamada em 1789, afirmando a igualdade jurídica e as liberdades individuais dos "cidadãos", foi instituído o governo do "terror" que suprimiu esses mesmos direitos. Ademais, de sua suposta universalidade foram inicialmente excluídos significativos segmentos, como pobres, minorias religiosas, mulheres, escravos, crianças, "loucos", prisioneiros e estrangeiros. Se o século 19 caracteriza-se pela barbárie colonial na periferia e superexploração e discriminação social, de gênero e étnica, também no centro do sistema capitalista, em nome da "civilização", mesmo após a DUDH, incontáveis atrocidades continuaram a ser perpetradas no "Sul Global" pelo imperialismo e colonialismo, como a transferência da violência para ele, tornado palco da guerra fria. Atestam isso as ditaduras na Ásia e América Latina, o colonialismo e o apartheid na África do Sul e Palestina e as guerras de libertação, confrontos e ingerências estrangeiras no Terceiro Mundo. Milhões foram excluídos e exterminados em nome de ideologias de "pureza racial", social ou étnica e da constituição do "novo-homem" e de "cidades perfeitas" (ENRIQUEZ, 2001).

No presente artigo revisamos criticamente a literatura especializada, comparando interpretações acerca da continuidade da violência e da barbárie na contemporaneidade, a despeito do avanço normativo e consolidação do DIDH. O texto divide-se em três blocos, bem-demarcados. Primeiramente, são apresentados autores (oriundos, sobretudo, das ciências jurídicas) que comentam os fundamentos dos direitos humanos e sua institucionalização como linguagem estatal positivista. Na sequência, problematizamos a ineficácia da arquite- 
tura protetiva internacional. O par conceitual dicotômico ("poder dos direitos" e "direitos de poder"), cunhado pelo jurista Richard Falk, garante a coerência teórica e textual, explicitando a complexidade da temática. A abordagem é finalizada associando, sobretudo a partir de teóricos das ciências humanas, as violações de direitos à própria lógica ambivalente da modernidade, fundada em princípios altissonantes contraditados por práticas torpes. É evidente que, mormente no século 20 , houve um avanço normativo e institucional para definir e proteger a dignidade humana. A continuidade da violência estatal e social, da vulnerabilidade concreta e negação de direitos básicos de amplos segmentos, contudo, problematiza a eficácia protetiva dos direitos humanos, evidenciando que sua trajetória não é linear e precisa ser compreendida em conexão com o campo econômico, cultural, social e político. A ênfase na "civilização" ou "barbárie", cuja interação é dialética, depende da teoria social e jurídica, que informa a interpretação de cada autor aqui discutido, mas é possível constatar, analisando o conjunto, que a realidade de parte da população mundial continua muito aquém dos avanços normativos que deveriam garantir uma vida digna e, com ela, a tão almejada paz social. Ainda vigoram diferentes formas de domínio, discriminação e hierarquias, parte da própria lógica da modernidade conforme alguns, o que compromete interpretações positivistas. Este artigo é fruto de tese de doutoramento, que teve como foco as violações de direitos humanos pelo Estado israelense.

\section{A CONSOLIDAÇÃO DOS DIREITOS HUMANOS, SUA FUNDAMENTAÇÃO E HORIZONTE UTÓPICO}

Historicizando os direitos humanos, Sidney Guerra (2011, p. 73-78) mostra que a DUDH adquiriu importância política no âmbito constitucional em esfera internacional, influenciando o conteúdo de diversas convenções, tratados, protocolos e declarações e incorporando um sentido de esperança e solidariedade na luta por igualdade e pelo fim da discriminação no mundo. A criação da ONU e a consolidação do DIDH levaram a uma profunda mudança nas relações internacionais e no comportamento dos Estados e atores sociais, dividindo-se a instauração da proteção internacional em três grandes momentos. Uma etapa normativa, indo do final da Segunda Guerra ao início dos anos 60, quando os direitos humanos foram internacionalizados por meio da Carta da ONU e da DUDH e o processo de descolonização foi acelerado. Segundo, até a queda do Muro de Berlim, sendo esta uma etapa de construção institucional, com o surgimento de órgãos e mecanismos de controle e efetivação assegurados em diferentes documentos - foram criados os comitês de direitos humanos, de prevenção do racismo, contra a tortura, para eliminação da discriminação contra as mulheres, além dos sistemas regionais e dos guardiões dos pactos internacionais. Terceiro, do término da guerra fria em diante, quando o final da bipolaridade deveria ter sido alvissareiro para uma maior cooperação internacional e efetivação dos direitos humanos em âmbito global, sendo o desenvolvimento normativo complementado em outras áreas, como infância, direito dos povos e minorias e administração da justiça, tornando-se as conferências mundiais de direitos humanos encontros massivos, reunindo entidades governamentais e não governamentais. Ainda segundo Guerra (2011, p. 82), o DIDH tornou-se um "[...] objeto autônomo do Direito Internacional Público, com instrumentos, órgãos e procedimentos de aplicação próprios, caracterizando-se essencialmente como um direito de proteção". Silva (2011) e Ali Mazrui (2010) des- 


\section{Humanos e}

Democracia

tacam o relevante papel desempenhado pelos países do "Terceiro Mundo" em consolidar o DIDH, descolonizando também a ONU ao garantir o reconhecimento e institucionalização de direitos, como o desenvolvimento e soberania sobre recursos nacionais, proscrevendo qualquer foram de colonialismo e racismo.

Por estar fundado na aceitação da subjetividade, igualdade e identidade universal dos indivíduos como pessoas humanas, possuidoras de direitos por sua própria existência e não em decorrência da pertença a determinado grupo, o DIDH se diferencia do direito internacional clássico, que ignora o indivíduo sujeito de direito e tem como pilares a soberania dos países, fundada nos princípios de reciprocidade, exclusividade da competência nacional, reversibilidade de compromissos e não ingerência em assuntos nacionais alheios (sistema westfaliano). Conforme Guerra (2011, p.83), a codificação do DIDH ocorreu "[...] principalmente pelo fato de o próprio Estado ser o maior violador desses direitos" (por ação ou omissão) e sob a pressuposição de que "[...] a sociedade internacional forma um todo e os seus interesses predominam sobre os dos Estados individualmente", implicando uma ressignificação da soberania e autonomia absoluta dos Estados. Reformulando os âmbitos legais nacionais, o DIDH estaria acomodando as tensões em "padrões primários supranacionais", apresentando-se como um "[...] instrumento vital para a uniformização, o fortalecimento e a implementação da dignidade da pessoa humana". No mesmo sentido, Flávia Piovesan, Ana Letícia Medeiros e Oscar Vieira (2008) ressaltam que a consumação e ampla aceitação desse sistema normativo internacional influenciou o "direito constitucional ocidental", que passou a incorporar e se orientar pelo princípio da dignidade humana, emergindo uma espécie de "vertente de constitucionalismo global", traduzida em aparatos internacionais de garantia dos direitos fundamentais e limitação do poder dos Estados ante a suas sociedades, o que constitui uma abordagem universalista da questão em oposição ao sistema westfaliano ou "soberanista".

Pelo menos em teoria, a tendência universalista deveria culminar em "Estados de direito democráticos, sociais e ambientais", amigáveis e cooperantes na esfera global, transitando da concepção hobbesiana de soberania, centrada no Estado, para a kantiana, de cidadania universal. Em oposição à ordem westfaliana, os Estados passaram a ser limitados em sua soberania dada a primazia da pessoa humana, como sujeito de direitos inerentes, inalienáveis e protegidos internacionalmente. Assim, diante da ambição normatizadora da sociedade global, as relações entre os Estados e seus cidadãos, ou entre governantes e governados, deixaram de ser problema meramente de jurisdição doméstica, tornando-se importante critério da legitimidade dos países e tema de legítimo interesse internacional, a fim de assegurar um "mínimo ético irredutível". Logo, o DIDH exerceu uma influência generalizada, buscando afetar todos os ramos do direito, com os Estados gradativamente aceitando limitações em sua soberania (RAMOS, 2005, p. 59).

Richard Falk (2009) assevera que, dentre outras coisas, o DIDH deslegitima governos violadores e provê a grupos de oposição um senso de legitimidade em suas lutas, estabelecendo vínculos de solidariedade entre ações domésticas e causas internacionais. Axiologicamente baseada na dignidade humana, a perspectiva universalista do DIDH marcaria o final da exclusividade dos Estados no trato de suas sociedades, impondo ao direito internacional o reconhecimento de um mínimo de direitos inderrogáveis a todo ser humano, consolidando uma ética universal que combina os valores da igualdade e da liberdade ao condensar e classificar 
como indivisíveis, universais e interdependentes direitos civis, políticos, econômicos, sociais e culturais, além dos direitos dos povos (autodeterminação, exploração dos recursos nacionais) e difusos e interpessoais (paz, desenvolvimento, meio ambiente adequado).

Se as origens filosóficas imediatas dos direitos humanos (especificamente, os direitos civis e políticos) remontam ao movimento iluminista, com os primeiros tratados e instituições reguladoras das guerras sendo criados ainda no século 19, é na segunda metade do 20 que o DIDH, como legislação internacional, ganha corpo e adesão da maioria dos Estados a diferentes instrumentos com seus sistemas de cumprimento, fiscalização e controle. Seu objetivo primordial: a afirmação de um referencial ético a orientar a humanidade, manter a paz e proteger a dignidade humana da barbárie difundida na modernidade. Afirma a lógica do razoável e o valor absoluto intrínseco às pessoas humanas, vistas como insubstituíveis e únicas, que devem ser tratadas como fim em si e fonte do direito. Interpretando a consolidação do DIDH, Fabio Konder Comparato (1999, p. 30-31) anuncia que a "[...] compreensão da dignidade suprema da pessoa humana e de seus direitos, no curso da história, tem sido, em grande parte, o fruto da dor física e do sofrimento moral". Logo, não seria fortuita a estruturação do DIDH justamente na sequência da Segunda Guerra Mundial e de suas atrocidades, havendo também uma sincronia entre os avanços legais e "as grandes descobertas científicas ou invenções técnicas". Já para Lynn Hunt (2009, p. 24-33), o reconhecimento dos direitos "inerentes" passaria pela empatia ou pelos canais físicos e emotivos. A afirmação e valorização da "integridade corporal", individualidade, igualdade e capacidade de autonomia dos sujeitos, seriam práticas culturais incorporadas do século 18 em diante, quando teria ocorrido uma revolução nas sensibilidades a partir de novas experiências (como exposições públicas de imagens e leitura de romances e de relatos que horrorizavam, como torturas), que teriam propiciado múltiplas interações, levando a mudanças socioculturais e políticas. Estas fundamentaram uma nova conceituação da humanidade pautada pelo reconhecimento de valores mínimos, preparando o terreno para a emergência dos direitos humanos.

Piovesan, Medeiros e Vieira (2008) e Silva (2011) também destacam na base do DIDH princípios kantianos, como autonomia, moralidade, dignidade, direito cosmopolita e paz perpétua, além da igualdade e não discriminação, sendo os direitos humanos comuns a todos e alheios à competência restritiva do Estado, portanto não alienáveis, delegáveis ou derrogáveis. Em suma, tomando de empréstimo a expressão de Norberto Bobbio, a "Era dos direitos" tem seu alicerce nesse sistema internacional de proteção dos direitos humanos, gradativamente consolidado e compreendido por instituições, procedimentos e mecanismos voltados à salvaguarda da dignidade humana, sendo esta o "[...] paradigma e referencial ético, verdadeiro superprincípio a orientar o constitucionalismo contemporâneo nas esferas local, regional e global" (PIOVESAN; MEDEIROS; VIEIRA, 2008). Como invenção humana e contínuo processo de construção e reconstrução, em um espaço simbólico de ação social, seriam direitos que surgem quando devem e podem surgir, compondo uma "racionalidade de resistência", uma "plataforma emancipatória", e traduzindo esforços de consolidação de espaços de luta pela dignidade humana. Diante da barbárie, seria uma construção consciente vocacionada a evitar sofrimentos e assegurar a dignidade das pessoas. Assim, os direitos humanos foram encampados como bandeira pelas diferentes sociedades, que constituíram um verdadeiro movimento internacional de direitos humanos, composto de variadas organizações de alcance tanto 


\section{Humanos e}

Democracia

global quanto meramente local, mas que partilham de um mesmo referencial legal e ético. A formulação e efetivação do DIDH, portanto, primeiramente via ONU e Estados-nacionais, também se tornou um projeto da "sociedade civil global". Inclusive, várias organizações passaram a participar ativamente das reuniões da ONU acompanhando sessões de sua Comissão de Direitos Humanos, pronunciando-se e emitindo relatórios e pareceres.

\section{CRIITICA À VIGÊNCIA DOS DIREITOS HUMANOS NA MODERNIDADE}

No século 21, no que diz respeito à legitimidade dos direitos humanos, prossegue o embate entre universalistas, relativistas culturais, críticos ao eurocentrismo da doutrina, e "soberanistas". Mais recentemente, a posição dos últimos foi fortalecida com a ascensão de governantes chauvinistas em diferentes países, que vêm criticando a ONU e os instrumentos e órgãos internacionais, não raro de forma burlesca, como intervencionistas, "comunistas" (caso brasileiro) ou contrários às supostas "tradições nacionais". Apesar das disputas, ainda há uma adesão majoritária no âmbito interestatal a esse referencial, nem que seja no âmbito estritamente discursivo. Ademais, ao menos entre universalistas, há certo consenso acerca dos fundamentos filosófico-transcendentais que justificam a dignidade humana, girando os questionamentos em torno da contradição entre, por um lado, o DIDH estar consolidado com suas diferentes áreas detalhadas e, por outro, continuar a não vigorar na prática para amplos segmentos populacionais, sendo o principal desafio político e social: efetivar direitos já assegurados ou evitar que "continuem a ser violados e anulados", o que não suprime a possibilidade de surgirem novos (CADEMARTORI; GRUBBA, 2012). Eis uma das conclusões das Conferências Mundiais de Direitos Humanos. Silva (2011) está entre os diversos autores a ressaltar que se a aprovação da DUDH contou com amplo e entusiasmado apoio e consenso, sua necessária transposição em instrumentos jurídicos internacionais de caráter obrigatório foi mais tortuosa e complexa. Além das divergências oriundas da guerra fria, plasmadas em concepções diferentes acerca do papel do Estado e do mercado na garantia de direitos, a insistência westfaliana no caráter soberano dos Estados atravancou o desenvolvimento e a execução plena desse referencial. Como resposta às alegadas violações, governos frequentemente invocaram a ilegitimidade das acusações e dos mecanismos estabelecidos pela ONU, bem como a impossibilidade de esta interferir em assuntos internos de seus membros.

Conforme Richard Falk (2009), se o governo Carter, nos EUA, deu primazia à defesa dos direitos humanos, interrompendo seu uso quase exclusivo como propaganda ideológica contra governos inimigos (mormente comunistas), tratou-se de um breve lapso, logo revertido por Reagan, que deu precedência aos alinhamentos estratégicos e ideológicos. Ambiguamente, os anos 90 testemunharam tanto a realização da Conferência Internacional de Direitos Humanos em Viena e o sucesso das lutas contra o apartheid e o autoritarismo no Leste Europeu, quanto o genocídio em Ruanda, a limpeza étnica nos Balcãs, intervenções humanitárias contestáveis e custosas em termos materiais e de vidas humanas (difundidas a partir da atuação não autorizada da Otan no Kosovo) e a difusão do neoliberalismo e da "globalização predatória", fragilizando a efetivação de direitos e levando a um aumento da desigualdade e da pobreza. Logo, a queda da URSS não marcou o "fim da história" e a ascensão da civilização conforme predisseram falsos profetas. Juntamente com a precarização da vida e a continuidade de discriminações e opressões sistemáticas, a guerra ao terror aprofundou a desestabili- 
zação do DIDH, difundindo conflitos a partir da lógica perversa de garantir a segurança global por meio da luta assimétrica e preemptiva de Estados soberanos contra agentes não estatais (redes transnacionais), ou sistemas vertebrados contra celulares, na linguagem de Arjun Appadurai (2009). Para este, as respostas estadunidenses não seriam um "efeito necessário", mas uma escolha moldada por "ambições geopolíticas" e "desafios securitários representados pelo megaterrorismo", destacando-se a flexibilização das soberanias com as invasões do Iraque e do Afeganistão e ações militares em vários outros países do Oriente Médio, além da legalização nos EUA e Israel da tortura e da transferência de presos políticos ("combatentes ilegais" ou "terroristas") para centros secretos de detenção, nos quais a arquitetura protetiva humanitária é letra morta (TODOROV, 2010). Outros autores são ainda mais críticos em suas reflexões sobre a guerra ao terror que, inclusive, recorreu a ações tipificáveis como terrorismo de Estado (CHOMSKY, 2006; LOSURDO, 2010). Se acrescentarmos a esse quadro o crescente número de refugiados econômicos, de guerras e ambientais, torna-se forçoso reconhecer a enorme distância que há até a efetivação do DIDH (cuja legislação é fragmentada, com temas múltiplos), e não há garantia alguma que isso venha a ocorrer; pelo contrário, os prognósticos são muito negativos, como veremos na sequência. O caso dos refugiados ilustra a questão: conforme dados da UNHCR (2019), agência especializada da ONU, as pessoas deslocadas à força no mundo totalizaram o número recorde de quase 71.000 .000 , com a grande maioria (80\%) vivendo em países vizinhos daquele de sua origem, portanto não nas Américas nem na Europa, mas na Ásia, África e Oriente Médio, com o "Terceiro Mundo" continuando a ser palco prioritário das violências e violações, tal qual na guerra fria. Somente para fins comparativos, enquanto a Alemanha e o Sudão abrigaram 1 milhão e 100 mil pessoas, a Uganda os superou em 100 mil, o Paquistão em 300 mil, destacando-se a Turquia, que mantém 3 milhões e 700 mil refugiados, sendo a média mundial de 37 mil pessoas por dia fugindo de suas casas.

Para compreender essas contradições na efetivação dos direitos humanos, Richard Falk (2009, p. 5-6, 16-17, 26, 34, 40, 143) forjou duas categorias ("poder dos direitos" e "direitos de poder") que articulam as partes do presente texto e permitem enquadrar os diferentes teóricos aqui revisados, que tanto criticam quanto defendem o DIDH. Por um lado, sobretudo da metade do século 20 em diante, a humanidade avançou na tradução dos princípios oriundos das revoluções liberais e socialistas em direitos legalmente assegurados. 0 controle normativo das ações dos Estados e a transformação destes em promotores de direitos, denota o "poder dos direitos", ensejando um potencial para mobilização moral e legal na luta por justiça global. Inclusive, com base nessa normatividade, governos e sociedades se mobilizaram na constituição de uma opinião pública global, defendendo uma ordem jurídica e geopolítica mais justa e horizontal, ou estruturas pós-westfalianas, mais bem expressas na Assembleia Geral da ONU, Fórum Social Mundial, Tribunal Penal Internacional e na rede internacional de entidades não governamentais. Dessa forma, o DIDH constituiu-se em referencial contra-hegemônico para reivindicações interseccionais de igualdade e crítica às discriminações das potências, fundamentando diferentes agendas progressistas que desafiam as formas prevalecentes de exclusão, opressão e exploração. Ou seja, é o principal arcabouço de resistência, não obstante certo "orientalismo" arraigado na bibliografia e na doutrina, tendo sido crucial para denúncias que desgastaram ditaduras, como na América Latina, e para a legitimação de 


\section{Humanos e}

Democracia

movimentos sociais, anticoloniais e globais, incluindo-se aí o reconhecimento internacional de movimentos de resistência e as mobilizações contra a colonização israelense e o apartheid na África do Sul.

De outro lado, contudo, estariam os "direitos de poder", ou "novas formas de hipocrisia", manipulações linguísticas e apropriações discursivas para legitimar a promoção de objetivos geopolíticos, maquiados de interesses supostamente universais. Tudo ao arrepio dos tratados internacionais concretamente ignorados por diferentes Estados (especialmente os big players), cuja ratificação não representaria mais do que um gesto performático e de boa vontade, que não impactou sua soberania e autonomia estatal, mantendo-se a lógica do sistema westfaliano e das assimetrias coloniais e pós-coloniais. Para Falk (2009), sua própria aprovação se explicaria pela garantia de não aplicação compulsória de suas normas, sendo paradigmática a natureza meramente "declaratória" da DUDH, apenas expressando anseios cuja realização seria voluntária no contexto dos Estados individualmente considerados (há interpretações destoantes). Ademais, comprometeria a efetivação do DIDH a prevalência das desigualdades e de discriminações, autoritarismo e neocolonialismo. Na perspectiva dos "direitos de poder, o DIDH seria um "diálogo global eurocêntrico", lembrando "intervenções militares em sua visão bifocal de abusos no Norte e no Sul", com atores políticos poderosos ou bem-relacionados, imunes à responsabilização criminal, atribuída somente a lideranças menos expressivas internacionalmente e sem valor estratégico para as potências, inclusive ex-aliados (Saddam Hussein, Osama Bin Laden, Muammar Kaddafi). "Atores hegemônicos" e seus aliados regionais gozariam, assim, de um "[...] direito de exceção informal, embora plenamente eficaz, no sentido de não adesão ao direito internacional [...]", coroado pelo poder de veto no Conselho de Segurança da ONU, este que, juntamente com a primazia da soberania estatal, seria um aspecto estrutural remanescente da "ordem mundial westfaliana". Apropriar-se-iam de forma hegemônica do discurso dos direitos humanos tanto Estados infratores, mas aliados do "Império", como Israel, quanto organizações internacionais formadas no "Ocidente" durante a guerra fria, como a Humans Rights Watch e Freedom House, cujas ações iniciais estiveram pautadas pela denúncia dos abusos praticados somente por inimigos ideológicos, sendo algumas ainda hoje duramente criticadas por produzirem relatorias dúbias, sobretudo no tocante às violações do direito internacional humanitário pelos EUA e aliados, caso da Anistia Internacional (DE ROOIJ, 2003). Generalizando suas conclusões acerca do caso palestino, Falk (2009) afirma que,

[...] essa estrutura sustentando a opressão e ofuscando várias formas de crueldade ficou explícita nas relações entre a Europa e o Oriente Médio e sul da Ásia durante o período colonial, mas persiste em muitos, mas não todos, caracteres pós-coloniais, ainda que frequentemente sob formas disfarçadas e inconsistentes [...] Esse padrão é definitivamente descritivo de muitas realidades intergovernamentais e inter-regionais, mas também de formas mais complicadas afetando uma infinidade de configurações intragovernamentais (p. 28, 30-31).

Em seu conjunto, portanto, o DIDH é mobilizado em dois sentidos opostos: como ferramenta contra-hegemônica de luta por direitos ou como meio de manutenção dos poderes e opressões, cumprindo função ideologizante em relação a essa estrutura assimétrica. $O$ direito internacional é tanto projeto da sociedade civil global e base comum de ação para diversos 
grupos, que fundamentam nele lutas por direitos, denúncias e pressões, quanto instrumento útil a atores estatais hegemônicos e violadores, que o encamparam como discurso legitimador e ocultador da continuidade de relações de poder e dominação assimétricas e nada altruístas em âmbito global.

Aprofundando a perspectiva pós-colonial do DIDH, podemos entender os "direitos de poder" também como a continuidade da retórica do "universalismo europeu", conceituado por Immanuel Wallerstein (2007, p. 30-43), que denuncia seus usos arbitrários, situando-os no quadro maior da expansão do sistema capitalista mundial e dos discursos empregados pelo "Ocidente" para justificar seu domínio sobre os povos "periféricos", caso da conquista da América. Na defesa conveniente e parcial dos direitos humanos, democracia e livre-mercado prosseguiria o discurso colonialista e universalista europeu dos séculos iniciais da modernidade, empregado em defesa dos interesses das classes dirigentes europeias. Nos séculos 20 e 21, esse "universalismo ocidental" continuou a se fundamentar em valores supostamente universais para legitimar e viabilizar interesses geopolíticos e econômicos concretos, porém velados, cumprindo tal função o direito autoatribuído das potências (sobretudo os EUA) de intervirem nos demais países, violando soberanias. Eis a hegemonia e seu verniz humanitário. Nada de novo sob o céu da modernidade, pois ainda há a velha lógica de justificar conquistas militares, exploração econômica e injustiças massivas em nome do pretenso "bem maior" da expansão da fé, progresso e civilização ("fardo do homem branco") para todos os povos, traduzidos agora em democracia e direitos humanos, mantendo-se a contradição entre o discurso e a prática. Essa imposição dos direitos humanos ainda se dá em conformidade com quatro argumentos básicos já utilizados para sustentar ideologicamente as "intervenções" dos civilizados junto aos selvagens: sua barbárie, a disseminação de valores universais, findar com práticas contrárias a eles (canibalismo, fundamentalismo, terrorismo) e defender inocentes ameaçados.

Justifica-se, assim, o desrespeito aos princípios de autodeterminação e soberania que a ONU deveria assegurar, com a ênfase no cumprimento dos direitos humanos, reinstituindo a legitimidade de intervenções seletivas como prerrogativa das potências para perseguir seus interesses escusos, mas com uma justificativa moral (lei natural e cristianismo, missão civilizadora ou democracia e direitos humanos). Vale ressaltar que essa ênfase de Wallerstein no "universalismo" como retórica de poder, que aparelha e se vale dos direitos humanos, não pode negar avanços concretos garantidos pelo "poder dos direitos" em questões dificilmente defensáveis por relativistas culturais, sendo um exemplo a luta contra a clitoridectomia em determinadas regiões, que conjuga lideranças feministas locais e internacionais como parte da "sociedade civil global". Ademais, as críticas de Falk (2009) e Wallerstein (2007, p. 60) não se dirigem às intervenções humanitárias em si, mas à falta delas em casos específicos (novamente a Palestina) e à arbitrariedade subjacente às experiências concretas, como nos casos médio-orientais, no novo milênio. Em suma, expressão dos "direitos de poder", o "universalismo europeu" seria uma "[...] doutrina moralmente ambígua. Ela ataca os crimes de alguns e passa por cima dos crimes de outros, apesar de usar os critérios de uma lei que se afirma natural", dando continuidade a uma retórica de poder que remonta à fundação do sistema capitalista mundial e foi aplicada, mormente, em sua periferia. 


\section{Humanos e \\ Democracia}

É possível aproximar dessas reflexões a teoria crítica dos direitos humanos, que é o lugar epistemológico para uma posição problematizadora e não eurocêntrica relativa ao DIDH, cuja efetiva consumação depende de sua realização como direitos dos oprimidos, pois os opressores, como tais, não podem ter direito algum. "Somente fazendo justiça aos povos e às classes oprimidas se propiciará seu verdadeiro bem comum e os direitos humanos realmente universais" - acrescente-se aí outras dimensões como raça, gênero e orientação sexual (MARTíNEZ, 2008, p. 38-42). O problema radical é a afirmação tanto da vida biológica quanto dos planos da liberdade, justiça, dignidade e solidariedade, em contraposição à supressão dos direitos nas diferentes esferas (pessoal, social, estrutural), sendo contraditório que somente poucos desfrutem de direitos considerados universais. A luta pelo DIDH, portanto, deve garantir justiça aos oprimidos por meio de uma práxis que supere as realidades negadoras, evitando uma "cultura anestesiada dos direitos humanos". Para Ignacio Ellacuría (apud MARTíNEZ, 2008, p. 38-42), se os direitos humanos representam ao mesmo tempo a superação do mal comum e a concretização do bem comum - sendo um momento ideologizado da práxis humana -, se não forem historicizados e verificados conforme suas consequências práticas para as vidas dos excluídos, descambarão em uma abstração predicada em princípios alheios à realidade, sendo manipulados para manter a opressão de muitos por poucos. Por mais que seja desejável sua efetivação, dado seu conteúdo libertário, tomar os direitos humanos como consumados sem verificar seu momento atual acaba por propiciar um uso ideologizado em favor dos poderosos, limitando-os ao benefício de um grupo restrito. Logo, há que se colocar à prova a dimensão universal do ser humano tal qual afirmada, contrapondo-a à situação realmente vivida pelos diferentes grupos. Há que se questionar para que e para quem são proclamados e quais são seus efeitos práticos, sendo o alvo privilegiado ou a realidade mais universal as maiorias oprimidas, para as quais os direitos humanos são negados de forma sistemática. É uma historicização dialética, considerando tanto a realidade negada quanto a realidade negadora, que permite averiguar as raízes mais profundas da negação (MARTíNEZ, 2008). Assim, Antonio Salamanca Serrano (2008, p. 137) faz a crítica ao que chama de expropriação do direito dos oprimidos à revolução, entendido como movimento de concretização dos direitos humanos e afirmação da própria vida contra o domínio colonial, degradação ambiental ou miséria, ainda que pela via armada, como as lutas anticoloniais. "Por isso, o direito humano à revolução é hoje, na maioria dos países, direito à reversão revolucionária de um sistema de relações mundiais que extermina a vida dos povos". Na mesma direção, mas atuando no campo historiográfico, Lynn Hunt (2009) contrapõe a retórica dos direitos humanos à realidade histórica, questionando sua propalada "autoevidência" e seu caráter supostamente "natural", "igualitário" e "universal", afirmando que somente se tornarão significativos quando adquirirem conteúdo político, passando a ser garantidos na prática.

Cabem salvaguardas em relação a essas abordagens críticas que, embora necessárias, válidas e potentes, se simplificadas recaem em um reducionismo dos impactos do DIDH, generalizando constatações para um conjunto complexo de mais de duzentas declarações, convenções, tratados e protocolos, com usos e eficácia variados. Ademais, a própria ONU, a partir da nova correlação de forças interna oriunda do ingresso dos países africanos e asiáticos dos anos 50 do século 20 em diante, reconheceu o direito à autodeclaração e autodeterminação dos povos e a legitimidade da luta contra o colonialismo e o racismo, inclusive por meios armados, tornando-se um instrumento progressivo e não regressivo ou conservador (SILVA, 2011). Tam- 
bém, como visto com Falk, apesar dos abusos e negações concretas, o DIDH constitui referencial legitimador da sociedade civil global nas lutas contra opressões e pela efetivação de direitos, provendo uma universalidade indispensável para reivindicar direitos e limitar e denunciar o poder das autoridades estatais, sendo meio privilegiado de resistência à barbárie.

\section{A MODERNIDADE E A BARBÁRIE}

Embora os direitos humanos como tal tenham sido normatizados e difundidos ao longo do século 20, ganhando legitimidade internacional e moldando os discursos e as constituições dos diferentes países, há evidências suficientes da permanência, senão avanço, da barbárie na modernidade e pós-modernidade, que sugerem uma maior cautela na apreciação geral dos supostos avanços da humanidade até então, tal qual defendido por positivistas. É o caso do holocausto, não exceção, mas fruto da modernidade (BAUMAN, 1998), "guerras religiosas" (HOBSBAWM, 1998), "práticas sociais genocidas" (FEIERSTEIN, 2011), guerras contra o terror e limpezas étnicas nos séculos 20 e 21 , que implicam demonização da alteridade e mobilização para o cometimento de atrocidades. Enquadra-se aí também o debate sobre a pós-democracia e o obscurantismo (CASARA, 2018), ou a generalização da vida nua e do estado de exceção (AGAMBEN, 2007).

Podemos pensar a contradição entre vigência teórica e ineficácia concreta do DIDH em nossos dias a partir de um paradoxo mais abrangente identificado por diferentes autores das ciências humanas: a dupla face das civilizações, rainhas da paz e da guerra, do amor e do ódio, ora manifestando Eros ora Tanatos (ENRIQUEZ, 2001). O sociólogo Anthony Giddens (1991, p. 15) define a civilização moderna como "[...] o estilo, costume de vida ou organização social que emergiu na Europa a partir do século XVII" e um fenômeno ambivalente, que se expandiu por todo o globo. O desenvolvimento e difusão mundial das instituições sociais modernas "[...] criaram oportunidades bem maiores para os seres humanos gozarem de uma existência segura e gratificante [...]". Porém, a modernidade também tem um lado sombrio, "[...] que se tornou muito aparente no século atual". É um potencial destrutivo, evidenciado nos efeitos ambientais gerados pelo desenvolvimento material e nos genocídios possibilitados pelo uso arbitrário do poder político e pelo desenvolvimento da capacidade destrutiva e "industrialização da guerra". Há ainda a possibilidade do totalitarismo, que combina poder político, militar e ideológico de uma forma sem precedentes antes do surgimento do Estado-nação. Nas palavras de Giddens (1991, p. 15), “O mundo em que vivemos hoje é um mundo carregado e perigoso. Isto tem servido para fazer mais do que simplesmente enfraquecer ou nos forçar a provar a suposição de que a emergência da modernidade levaria à formação de uma ordem social mais feliz e mais segura". A atualidade da barbárie também foi sublinhada pelo filósofo Herbert Marcuse (1975, p. 26-27):

[...] o progresso intensificado parece estar vinculado a uma igualmente intensificada ausência de liberdade. Por todo o mundo da civilização industrial, o domínio do homem pelo homem cresce em âmbito e eficiência. Essa tendência tampouco se apresenta como uma regressão incidental, transitória, na senda do progresso. Os campos de concentração, extermínios em massa, guerras mundiais e bombas atômicas não são recaídas no barbarismo, mas a implementação irreprimida das conquistas da ciência moderna, da tecnologia e dominação dos nossos tempos. E a mais eficaz subjugação e destruição do 


\section{Humanos e \\ Democracia}

homem pelo homem tem lugar no apogeu da civilização, quando as realizações materiais e intelectuais da humanidade parecem permitir a criação de um mundo verdadeiramente livre.

Considerando os assassinatos coletivos, o psicanalista Eugène Enriquez (2001, p. 15-16) parte da pressuposição de Freud de haver uma tendência humana a matar, humilhar e glorificar tal ato, tratando-se de uma "pulsão à destruição". Esse "desejo de matar" engendraria a proibição, corporificada em leis e instituições, inicialmente interditando sua prática em relação aos membros da tribo ou nação. $O$ interdito induziria à transgressão como fator que humaniza a sociedade, tornada capaz de "progresso na civilização": "[...] A transgressão à proibição de matar, resultando no assassinato, é parte integrante do trabalho civilizador". Este seria composto simultaneamente por uma responsabilidade sectária de cada um diante do outro e pelo não reconhecimento da unidade do conjunto humano, ocasionando "[...] violação da face do outro, criação de estruturas de rejeição, de repulsa, favorecendo em cada grupo a construção de uma identidade própria". Para Enriquez (2001, p. 15-16), "[...] o século XX, depois da grande carnificina de 1914-1918, será conhecido pelos genocídios" e, em seu transcurso, um princípio de legitimidade foi conferido aos assassinatos em massa, com a humanidade passando a aceitar com mais facilidade o desaparecimento dos diferentes sob a justificativa de impureza, fraqueza ou força fantasmagoricamente imaginada.

Ponderando sobre a "faceta sombria da modernidade", o também sociólogo, Zygmunt Bauman (1998, p. 30), destaca que, "[...] nenhuma das condições que tornaram Auschwitz possível realmente desapareceu e nenhuma medida efetiva foi tomada para evitar que tais possibilidades e princípios gerem catástrofes semelhantes". Esse fenômeno paradigmático da barbárie teria ocorrido a partir de uma concatenação peculiar de elementos ordinários da modernidade, que, por ainda estarem presentes, tornam possível a ocorrência de atrocidades semelhantes, destacando-se o efeito desumanizador da burocracia, o monopólio da violência e as ambições de "ajardinamento" ou engenharia social dos Estados modernos. Assim, nem sanha assassina coletiva nem desvio circunstancial de uma suposta marcha irrefreável rumo à civilização, "O Holocausto foi um choque único entre as velhas tensões que a modernidade ignorou, negligenciou ou não conseguiu resolver e os poderosos instrumentos de ação racional e efetiva que o próprio desenvolvimento moderno fez surgir" (BAUMAN, 1998, p. 16).

O mundo dos campos da morte e a sociedade que engendra revelam o lado progressivamente mais obscuro da civilização judaico-cristã. Civilização significa escravidão, guerras, exploração e campos da morte. Também significa higiene médica, elevadas ideias religiosas, belas artes e requintada música. É um erro imaginar que civilização e crueldade selvagem sejam antíteses... Em nosso tempo as crueldades, como muitos outros aspectos do nosso mundo, passaram a ser administradas de maneira muito mais efetiva que em qualquer época anterior. Não deixaram e não deixarão de existir. Tanto a criação como a destruição são aspectos inseparáveis do que chamamos civilização (RUBENSTEIN, 1978 apud BAUMAN, 1998, p. 27).

O potencial destrutivo inerente aos Estados-nacionais, a principal instituição política da modernidade, é identificado ainda por tantos outros autores. Para Falk (2009, p. 71-74), ao mesmo tempo em que eles conferem nacionalidade, permitindo, assim, aos indivíduos transitarem em um mundo de controle de fluxos e fronteiras, os Estados nacionais sustentam 
identidades específicas, excluindo minorias e facilmente se tornando instrumentos de opressão e afirmação coletiva sobre o outro, vulnerabilizando-o. Os governos ainda têm o poder, especialmente os de Estados hegemônicos, de violar o DIDH, carecendo a comunidade internacional de meios e mandato político efetivo de proteção - vide a falta de consenso em torno do TPI e a primazia dada aos instrumentos nacionais de investigação e punição. Salvo exceções, as organizações pós-westfalianas ainda não protegem eficazmente contra abusos estatais, com as limpezas étnicas e genocídios, embora criminalizados, não sendo prevenidos nem reprimidos de forma eficaz, restando ao sujeito e/ou grupo visado a proteção garantida pela estrutura da autoridade estatal, que, geralmente, está em mãos dos próprios violadores.

O historiador Eric Hobsbawm (1998, p. 268-272) afirma que, durante a maior parte do século 20, a barbárie se propagou e não há indícios de que esteja recuando. Múltiplos fatores levaram ao declínio dos valores iluministas, desestabilizando os pilares de sustentação dos direitos humanos. As "guerras civilizadas" nos campos de batalha foram sucedidas por guerras totais, justificadas a partir da necessária demonização dos inimigos para mobilizar e gerar adesão em países democráticos, conduzindo, assim, suas sociedades a guerras sem discernimento entre civis e militares, fundadas na oposição maniqueísta do bem contra o mal e na necessidade de vitória total, independentemente dos meios a serem empregados. Os esforços para negativar o outro geralmente conduziram a sua redução a um patamar sub-humano, sendo ele representado como uma ameaça ao corpo puro e são da nação, o que legitimou a supressão de seus direitos e facilitou sua extirpação física e simbólica. A Primeira Guerra foi o ponto de inflexão da "descida para a barbárie" e início da "era mais assassina da história", na qual o morticínio foi banalizado, criando um "depósito obscuro de crueldade e violência". "O século XX é o século da guerra, com um número de conflitos militares sérios envolvendo perdas substanciais de vidas consideravelmente mais alto do que em qualquer um dos dois séculos precedentes", afirma Giddens (1991, p. 15).

Para outro cientista social, Arjun Appadurai (2009, p. 36-37), o mundo pós-guerra fria, ao invés da pacificação e prosperidade esperadas com o suposto "fim da história", caracteriza-se por guerras civis e cívicas, às vezes tornadas cotidiano. Em diferentes contextos nacionais e regionais, campanhas intensas de violência encontram seu fundamento no medo. A globalização não eliminou o Estado nacional, com sua "ideia fundamental e perigosa": a defesa de posições étnico-nacionalistas ou da "soberania nacional baseada em uma etnicidade", fortalecendo-se os fundamentalismos, indigenismos e "majoritarianismos", com seu "narcisismo das diferenças menores", "ansiedade da incompletude" e "identidades predatórias" portadoras das "sementes do genocídio". Continua a vigorar o Estado-nação moderno, com sua "inerente tendência etnicida", criado e naturalizado por meio de guerras, exclusões ou extermínios e regras de subordinação, homogeneização educacional e linguística. Dessa forma, prevaleceriam, na "alta globalização", dois tipos de violência praticados por motivos culturais: a de movimentos etnonacionalistas (mormente limpezas étnicas) e aquela relacionada ao terrorismo e à "guerra ao terror", além das reações e defesas do exclusivismo e intervenção estatal ante a ingerência da globalização e do neoliberalismo.

Destarte, também para Appadurai (2009), em decorrência da persistência dessas identidades duras em um universo de fronteiras permeáveis, identidades móveis e tecnologias e fluxos rápidos, a "alta globalização" é um período de violência em grande escala, em várias 


\section{Humanos e \\ Democracia}

sociedades e regimes políticos, sobretudo intraestado. O campo cultural tornou-se o campo principal dos delírios de pureza, autenticidade, fronteiras e segurança. A ascensão neofascista e ultraconservadora no Brasil contemporâneo corrobora tal argumentação. Aprofundam-se as desigualdades entre nações, classes e regiões, o capital financeiro e especulativo flexibiliza soberanias e o Estado-nação vai perdendo sua força e se reduzindo à ficção de seu etnos como último recurso cultural. Paralelamente, outros fatores globais acompanham as transformações socioeconômicas, como a continuidade da violência contra mulheres, deslocamentos forçados de populações pobres, violência policial, tráfico de órgãos, drogas e armas, difusão de mercenários, ataques contra minorias e o trabalho infantil, sendo suas piores formas a prostituição e o alistamento em milícias civis ou militares. Nesse cenário pós-guerra fria, projetos utópicos e outros fatores têm alimentado processos opressivos e mortíferos em muitos países, desacreditando os mitos da globalização como integração ilimitada e do livre-comércio e intenso fluxo de capitais com efeitos somente positivos.

Para compreender de uma forma teórica essas contradições dos séculos 20 e 21, a "era mais assassina da história", mas que também consolida o DIDH, cabe mencionar as reflexões de outro cientista social, Daniel Feierstein (2011, p. 111-117), muito influenciado por Michel Foucault, Giorgio Agamben e outros. Ele aborda a modernidade como um sistema de poder, que conjuga de maneira multiforme no tempo e no espaço tecnologias específicas de destruição e reconstrução das relações sociais, capazes de manter a hegemonia dos grupos dominantes. Trata-se de diagramas de poder operados pelo soberano de forma a criar e manipular identidades e representações hegemônicas úteis para o controle de populações. Ao considerar a modernidade como sistema de poder e de controle, Feierstein agrupa suas contradições em três eixos básicos ou questões, oriundas de mudanças estruturais nas formas de representar o mundo e a si mesmo. "Igualdade", "soberania" e "autonomia" foram funcionais na ruptura com a sociedade estamental, com o sistema do Antigo Regime e na transição para a modernidade e legitimação desta, assim como para a consolidação dos direitos humanos. Tais fundamentos, contudo, também geraram efeitos inesperados, dado o descompasso entre o discurso explícito da modernidade e as práticas históricas concretas violadoras dos valores alardeados. À medida que princípios como autonomia, soberania e igualdade sustentaram a análise idealizada legitimadora, eles foram contraditados pela continuação da dominação de povos sobre povos, classes sobre classes, surgindo rachaduras nas estruturas de consenso, racionalidade e legitimidade do próprio sistema. Consolidando a modernidade como sistema de poder incoerente com seus próprios postulados, foram elaborados sistemas explicativos, como o racismo, e desenvolvidos e empregados distintos "procedimentos funcionais", como as práticas sociais genocidas operadas pelo nazismo, ditadura argentina (FEIERSTEIN, 2011) e na Faixa de Gaza (SAHD, 2012).

Em outras palavras, na medida em que na modernidade várias sociedades padronizaram a igualdade e proteção jurídica como alicerces de suas instituições e em conformidade com o DIDH, elas têm sido efetiva e corriqueiramente suprimidas, o que fica explícito na vida negada dos proscritos sociais. Se estes formalmente gozam de todos os direitos assegurados pelo Estado e por entidades internacionais, na prática "[...] sofrem a suspensão real, gradual ou extrema, dos direitos fundamentais para uma 'vida digna'". Estariam assim em uma "situação de inclusão excludente" no ordenamento jurídico, que "[...] expõe a vida humana a uma 
flagrante contradição, ela é protegida formalmente pelo direito enquanto é negada realmente pela suspensão prática dos direitos", situando-se essa vida em um quadro de exceção legal, seja por meio de decreto formal de excepcionalidade, seja por políticas extraoficiais cada vez mais comuns. É a vida nua de sujeitos vulneráveis, expostos à negação sistemática de direitos socioeconômicos e à arbitrariedade do poder e da violência (logo, sem direitos civis elementares), embora sejam, formalmente, reconhecidos como sujeitos de direito, ao menos na maioria dos casos (RUIZ, 2007, p. 29; AGAMBEN, 2007).

É uma vida paradoxal, normalizada no ato da exclusão e excluída sob a forma de suspensão normal dos direitos. A vida do excluído desvela as incongruências e insuficiências da igualdade formal do Estado de direito enquanto este normaliza a suspensão real dos direitos. Ela se encontra exposta no limite da vulnerabilidade e, nesse limite, desmascara as artimanhas das formalidades jurídicas do Estado de direito quando são utilizadas como artifícios legitimadores da exclusão, reduzindo a vida excluída à normalidade incluída na ordem (RUIZ, 2007, p. 29).

O paradoxo da igualdade e da proteção formal, contrapostas à desigualdade e à vulnerabilidade real da vida excluída, significa a suspensão de fato do direito. A vida do excluído encontra-se, assim, no limite de sua sobrevivência, exposta à injustiça e ao arbítrio estrutural. No limiar da vida e da morte, esses sujeitos sofrem uma suspensão de seus direitos fundamentais, excluindo-se a vida humana do ordenamento jurídico e mesmo da existência física ao incluir prerrogativas para vulnerabilizá-la (como decreto de estado de sítio, políticas de execução extrajudicial ou reclusão em campos, como espaços de vigência permanente da exceção legal e vulnerabilidade). Assim, seu sofrimento e morte por inanição são tornados fatos normais da dinâmica social, que não se tornam processos judiciais, exemplificando as execuções extrajudiciais de centenas de manifestantes palestinos em Gaza, ao longo de 2018. Tal lógica é coextensiva a miseráveis, refugiados e minorias.

Uma última chave teórica para considerar a fragilidade dos direitos humanos no mundo contemporâneo é o colonialismo e a colonialidade (campo dos estudos pós-coloniais, ao qual pertence Wallerstein e cujas considerações estão presentes nos "direitos do poder" de Falk). Esmiuçando a herança legada pela colonização europeia ou “ocidental”, Anibal Quijano (2010, p. 84) discerne colonialismo e colonialidade, vinculando-os à emergência do capitalismo e à colonização das Américas. O primeiro refere-se estritamente à estrutura de dominação/exploração, controle da autoridade política, do trabalho e da produção de uma população por outra de identidade diferente, cuja sede de suas instituições está localizada territorialmente em outro lugar. Se o colonialismo é mais antigo, a colonialidade é engendrada a partir dele, sendo "mais profunda e duradoura" e se caracterizando pelo estabelecimento de relações racistas de poder. "É um dos elementos constitutivos e específicos do padrão mundial do poder capitalista". Sustenta-se por meio da imposição de uma "[...] classificação racial/étnica da população do mundo como pedra angular do referido padrão de poder e opera em cada um dos planos, meios e dimensões, materiais e subjetivos, da existência social cotidiana e da escala societal. Origina-se e mundializa-se a partir da América", cuja colonização é coetânea e parte do mesmo movimento histórico de emergência e internacionalização do capitalismo centrado hegemonicamente naquele momento na Europa. "Em pouco tempo, com a América (Latina) o capitalismo torna-se mundial, eurocentrado, e a colonialidade e modernidade instalam-se 


\section{Humanos e \\ Democracia}

associadas como eixos constitutivos de seu específico padrão de poder, até hoje". Os vínculos entre colonialismo, capitalismo e modernidade também são identificados por Nelson Maldonado-Torres (2010, p. 414-417) e Enrique Dussel (2010), para quem o século 16 é ignorado pela filosofia moderna centroeuropeia, ainda que esteja na gênese da modernidade. Nele se encontraria a fundamentação da práxis de dominação colonial transoceânica - "colonialidade" -, que é simultânea à própria origem da modernidade.

A libertação política dos territórios coloniais remanescentes nos anos 70 - como as ex-colônias portuguesas, a Namíbia e o Zimbabwe - não teria esgotado por completo as consequências do colonialismo. Após as independências, caberia ainda combater as amarras econômicas (ou neocolonialismo) e empreender a descolonização cultural e epistemológica. Para reverter as relações sociais extremamente desiguais geradas pelo colonialismo (entre Estados e no interior destes, entre as classes e grupos sociais que os compõem), seria necessário suprimir a "colonialidade de poder e de saber". Os entraves materiais a serem debelados, em linhas gerais, seriam o neoliberalismo, a globalização assimétrica e os fluxos ininterruptos de capital, responsáveis pelo aumento das desigualdades e flexibilização das fronteiras e soberanias nacionais. Quanto à questão cultural e epistemológica, desde a conquista das Américas teria sido formulada uma concepção de mundo dominante, assentada em uma dupla diferença: cultural - haveria um mundo moderno, cristão e ocidental e o resto - e política (decorrente do imperialismo e capitalismo, ou centro e periferia de um "sistema mundo moderno"). Nas palavras de Santos e Meneses (2010, p. 19), "O colonialismo, para além de todas as dominações por que é conhecido, foi também uma dominação epistemológica, uma relação extremamente desigual de saber-poder que conduziu a uma supressão de muitas formas de saber próprias dos povos e/ou nações colonizados".

Essa visão reducionista de corte hegemônico do "pensamento moderno ocidental" seria "abissal". Tratar-se-ia de um sistema dualista de distinções visíveis e invisíveis, que impede a coexistência das partes, produzindo e radicalizando diferenciações. As distinções invisíveis fundamentam as visíveis e são estabelecidas a partir de linhas absolutas que dividem a realidade social em dois universos: nós, os civilizados, para cá da linha demarcatória, e eles, os bárbaros, para lá da fronteira. Estes desaparecem enquanto realidade, sendo considerados inexistentes, irrelevantes ou incompreensíveis, negados ou identificados com o passado deste lado da linha. Pelo contato hegemônico, a simultaneidade das existências cede lugar a não contemporaneidade. Essa linearidade falaciosa e supressora da alteridade (ou teleologia fabricada pelo "Ocidente" e aplicável à humanidade) sustenta a suposta universalidade dos princípios epistemológicos e jurídicos, aplicáveis somente ao lado de cá da linha, como os direitos humanos. Assim, é legitimado o exercício da violência e da apropriação no campo do conhecimento e do direito. Essa negação, esse esgotamento do outro, possibilita a prevalência desse "lado da linha" para além da qual há somente inexistência, invisibilidade e ausência não dialética. Aqui vigora a lei, lá sua ausência, permitindo-se todo tipo de violência e rapinagem. A modernidade ocidental fundamenta-se, para os "civilizados", na tensão entre os princípios de regulação (Estado, comunidade e mercado) e emancipação social. Essa dicotomia regulação/emancipação contempla unicamente a civilização (ou metrópoles), cabendo ao "lado de lá" da linha abissal outra fundada na apropriação/violência. No campo do direito, temos um lado caracterizado pela legalidade ou ilegalidade dos fenômenos e outro onde essa 
lógica é impensável como princípio organizador, pois são terras sem lei, foras da lei, a-legais ou com critérios de legalidade não oficialmente reconhecidos, portanto os direitos humanos podem ser violados impunemente.

Originalmente, esse outro espaço - ou "lado de lá da linha" - correspondeu às zonas coloniais, nas quais inexistiriam (ou seriam inválidos ou não reconhecidos) os termos verdadeiro ou falso, legal ou ilegal. Na modernidade, ao invés do abandono da barbárie em prol da civilização, teriam coexistido essas duas zonas ou categorias, separadas por uma linha abissal com base no olhar hegemônico do lado de cá (“Ocidente"). Logo, a dicotomia regulação/emancipação coexiste com a apropriação/violência, sendo possível entender a partir daí a eficácia ou não do DIDH, operado como "direitos de poder" (reificando ele mesmo a barbárie) ou "poder dos direitos", o que está em consonância com as reflexões de Santos e Meneses (2010) que, igualmente, aponta a dualidade dos direitos humanos como discurso colonial de opressão ou meio de luta contra-hegemônica. No campo do direito, a violência/apropriação reconhece não o direito das pessoas, mas somente o das coisas, implicando tráfico de escravos, trabaIho forçado, manipulação das leis e autoridades locais, pilhagem, deslocamento maciço de populações, guerras, tratados desiguais, formas distintas de apartheid e assimilação forçada. Como, todavia, essas arbitrariedades ocorrem na parte sub-humana, elas não colocam em causa os princípios da "humanidade", a não ser quando convém aos interesses escusos das potências, que então mobilizam sua retórica universalista. Essas carências produzem uma ausência radical de humanidade que cria a sub-humanidade moderna, na qual a exclusão se radicaliza à medida que é tornada inexistente, dado que os sub-humanos não são sequer candidatos à inclusão social. Essa negação do outro é imprescindível para a afirmação da "humanidade moderna" como universal e, para Santos e Meneses (2010, p. 39), essa realidade excludente seria tão verdadeira hoje quanto foi no período da ocupação colonial. "As colônias representam um modelo de exclusão radical que permanece atualmente no pensamento e práticas modernas ocidentais tal como aconteceu no ciclo colonial". Continua presente nas práticas e princípios hegemônicos a criação de "outros lados da linha" como não territórios (espaços sem lei, direitos humanos e democracia) e sua negação simultânea. Guantánamo e prisões similares, como no Afeganistão e em Israel/Palestina, seriam "as manifestações mais grotescas do pensamento jurídico abissal".

Se as linhas globais abissais foram ameaçadas frontalmente com as revoltas anticoloniais, parecendo que iriam desaparecer, contrariando essas expectativas logo após teve início uma expansão da barbárie, um redimensionamento e ampliação dos espaços de apropriação/ violência (coloniais), que passaram a incluir e "contaminar" partes dos territórios outrora situados "do lado de cá da linha" e do princípio de regulação/emancipação. Isso vem ocorrendo como forma de regular o que é percebido como uma "intromissão ameaçadora do colonial nas sociedades metropolitanas", sobretudo o terrorista, o imigrante indocumentado e o refugiado (presentes ou relacionados a grupos locais), cada um trazendo consigo a linha abissal global que caracteriza a exclusão radical e a inexistência jurídica. Seguindo essa linha de raciocínio, como o colonizado estaria dentro das próprias metrópoles, seria necessário um encurtamento e redefinição das fronteiras, bem como a "invisibilização" desse processo e dos territórios sub-humanos. Para Santos e Meneses (2010), as expressões mais peculiares dessa nova situação seriam o "muro da segregação israelita" e a categoria de "combatente ilegal" criada 


\section{Humanos e}

Democracia

nos Estados Unidos após o Onze de Setembro, além dos campos de refugiados. A exceção legal é decretada sem a suspensão dos direitos e garantias constitucionais. Quase imperceptivelmente, retroagem as garantias democráticas e de direitos humanos sob pretexto de assegurá-las. Nas áreas outrora colonizadas ou mesmo metropolitanas, há também um retorno de práticas políticas coloniais, como o governo indireto (agora por meio da privatização de serviços essenciais ou mesmo desregulamentação e restrição do Estado). Santos e Meneses (2010) recorrem à ideia de ascensão de "fascismos sociais" (plurais) à sombra do contrato social, que não somente coexiste, mas trivializa as democracias liberais para promover o capitalismo e manter as desigualdades. Seriam sociedades politicamente democráticas e socialmente fascistas nas quais coexiste normalidade constitucional (para os cidadãos do lado de cá) com estado de exceção (para os subalternos ou sub-humanos), o que corresponde perfeitamente ao cenário eleitoral consumado no Brasil em 2018.

Por fim, as crescentes violações e negações de direitos também devem ser pensadas a partir do atual estágio do sistema capitalista global, que, após um interlúdio relativamente progressista, no qual se tentou uma pactuação de classes por meio do Estado de Bem Estar Social, voltou, com o neoliberalismo, à mercantilização de todas as dimensões da vida, resultando em diferentes formas de negação, destruição e "expulsões" (SASSEN, 2016), catástrofe ambiental sistêmica e retirada gradativa de direitos (MÉSZÁROS, 2011) e/ou no advento de "Estados Pós-Democráticos", caracterizados pela "máxima desumanização inerente à lógica do capital, que se fundamenta na competição, no individualismo e na busca do lucro sem limites" (CASARA, 2018, p. 40).

\section{CONCLUSÃO}

Expusemos como, após as barbáries praticadas durante a Segunda Guerra Mundial, os direitos humanos e humanitários foram gradativamente codificados e assumidos em âmbito global como meio de salvaguardar a dignidade humana, estruturando uma arquitetura protetiva internacional (o DIDH), mas seu avanço não foi linear, nem absoluto, caracterizando-se pela não vigência de fato em várias localidades até hoje. Até a presente época, apesar de avanços, a depender da identidade dos envolvidos, as leis e instituições internacionais são ignoradas, com as potências não arcando com as consequências das violações cometidas principalmente contra as populações do "Sul global". Para a compreensão desses fatos recorremos à historicização dos direitos humanos, com análises mais lineares, idealistas, mas atribuímos centralidade às contribuições dos estudos pós-coloniais e da teoria crítica dos direitos humanos, que serviram de contraponto, assim como as reflexões críticas de cientistas humanos e sociais, que auxiliaram no entendimento teórico das violações a partir das próprias contradições inerentes à modernidade, contexto de surgimento dos direitos humanos, mas também de propagação irrefreável da barbárie. A ambivalência da modernidade, associada à polarização entre "direitos de poder" e "poder dos direitos", garantiu uma aproximação possível e explicação dessa realidade complexa, em que o mesmo referencial é utilizado de forma hegemônica e contra-hegemônica.

Concluímos, junto aos teóricos críticos, que é ilusão apostar na marcha irrefreável para o progresso, com os sublimes princípios constituintes do DIDH sendo efetivados por meio da boa vontade de governos e grupos dominantes. Para ser bem-entendido em uma sociedade 
capitalista, ou os direitos humanos são encarados e enaltecidos por seu valor de uso, como horizonte de luta, ferramenta e referencial contra-hegemônico, ou continuaremos a conviver com a barbárie associada a sua interpretação como mero valor de troca ou retórica do poder. O que está em jogo é uma disputa política, cabendo o fortalecimento da sociedade civil global para a tornar robusta o suficiente para exercer pressão e romper com a atual lógica social, econômica e política dominante. Diferentemente, porém, do reducionismo e pessimismo subjacente a algumas análises, que apontam para o sepultamento do Estado Democrático de Direito ou jogam o bebê junto com a água do banho, concordamos, no cômputo final, que a lógica do "poder dos direitos" ainda embasa diferentes formas de resistência e dá sentido a um projeto progressista comum em curso, que, mais do que nunca, precisamos incorporar, dado sua necessidade para a garantia da dignidade humana. Passadas décadas da fundação da ONU e promulgação da DUDH, com várias violações, está claro que os direitos humanos devem ser entendidos e reivindicados como direitos dos oprimidos, pois asseguram as próprias condições para a luta em prol da realização da dignidade humana, ainda que seu sentido seja esvaziado por poderes estabelecidos. Ao fim e ao cabo, o DIDH é um dado de uma realidade dialética que precisa ser compreendido em seu movimento (e foi isso que aqui intentamos), ao invés de uma tomada de posição definitiva sobre a coisa em si. Fazendo um juízo político, ainda nos parece sintoma de lucidez valorizar o potencial libertário do conjunto ou o "poder dos direitos".

\section{REFERÊNCIAS}

AGAMBEN, G. Homo Sacer: o poder soberano e a vida nua. Belo Horizonte: Editora UFMG, 2007.

APPADURAI, A. O medo ao pequeno número: ensaio sobre a geografia da raiva. São Paulo: lluminuras, 2009.

BAUMAN, Z. Modernidade e holocausto. Rio de Janeiro: Jorge Zahar Ed., 1998.

CADEMARTORI, L. H. U.; GRUBBA, L. S. O embasamento dos direitos humanos e sua relação com os direitos fundamentais a partir do diálogo garantista com a teoria da reinvenção dos direitos humanos. Revista Direito FGV, v. 8, n. 2. São Paulo, jul./dez. 2012. Disponível em: http://www.scielo.br/scielo.php?script=sci_arttext\&pi$\mathrm{d}=\mathrm{S} 1808-24322012000200013$. Acesso em: 25 nov. 2015.

CASARA, R. R. R. Estado pós-democrático: neo-obscurantismo e gestão dos indesejáveis. 3. ed. Rio de Janeiro: Civilização Brasileira, 2018.CHOMSKY, Noam. Piratas e imperadores: antigos e modernos: o terrorismo internacional no mundo real. Rio de Janeiro: Bertrand Brasil, 2006.COMPARATO, F. K. A afirmação histórica dos direitos humanos. São Paulo: Saraiva, 1999.

DE ROOIJ, P. Amnesty International: The Case of a Rape Foretold. Palestine: Information with Provenance (PIWP database), 2003. Disponível em: http://cosmos.ucc.ie/cs1064/jabowen/IPSC/articles/article0004850.html. Acesso em: 26 jul. 2019.

DUSSEL, E. Meditações anticartesianas sobre a origem do antidiscurso filosófico da modernidade. In: SANTOS, B. de S.; MENESES, M. P. (org.). Epistemologias do sul. São Paulo: Cortez, 2010.

ENRIQUEZ, E. Matar sem remorso: reflexões sobre os assassinatos coletivos. História: Questões \& Debates, Curitiba, v. 18, n. 35, p. 11-41, jul./dez. 2001.

FALK, R. Achieving human rights. New York: Routledge, 2009.

FEIERSTEIN, D. El genocidio como práctica social: entre el nazismo y la experiencia argentina. 2. ed. Buenos Aires: Fondo de Cultura Económica, 2011.GIDDENS, A. As consequências da modernidade. São Paulo: Editora Unesp, 1991.GUERRA, S. Direito internacional dos direitos humanos. São Paulo: Saraiva, 2011.

HOBSBAWM, E. J. Sobre a história. São Paulo: Companhia das Letras, 1998.

HUNT, L. A invenção dos direitos humanos: uma história. São Paulo: Companhia das Letras, 2009.

LOSURDO, D. A linguagem do império: léxico da ideologia estadunidense. Tradução Jaime A. Clasen. São Paulo: Boitempo, 2010.MARCUSE, H. Eros e civilização: uma interpretação filosófica do pensamento de Freud. Rio de Janeiro: Zahar Editores, 1975. 


\section{Humanos e \\ Democracia}

MALDONADO-TORRES, N. A topologia do ser e a geopolítica do conhecimento. Modernidade, império e colonialidade. In: SANTOS, B. de S.; MENESES, M. P. (org.). Epistemologias do sul. São Paulo: Cortez, 2010.

MARTÍNEZ, A. R. Derechos humanos, liberación y filosofía de la realidad histórica. In: MARTíNEZ, A. R. et al. Teoria crítica dos direitos humanos no século XXI. Porto Alegre: EDIPUCRS, 2008.

MAZRUI, A. A. "Procurai primeiramente o reino político". In: MAZRUI, A. A.; WONDJI, C. História geral da África. Brasília: Unesco, 2010.

MÉSZÁROS, I. O desafio e o fardo do tempo histórico. São Paulo: Boitempo, 2011.

PIOVESAN, F.; MEDEIROS, A. L. B.; VIEIRA, O. V. Introdução à parte I. In: PIOVESAN, F. (org.). Código de direito internacional dos direitos humanos anotado. São Paulo: DPJ Editora, 2008.

QUIJANO, A. Colonialidade do poder e classificação social. In: SANTOS, B. de S.; MENESES, Maria Paula (org.). Epistemologias do sul. São Paulo: Cortez, 2010.RAMOS, A. de C. Teoria geral dos direitos humanos na ordem internacional. Rio de Janeiro: Renovar, 2005.

RUIZ, C. B. As estratégias do (bio) poder na inclusão/excludente da vida humana. Revista Ethica, Rio de Janeiro, v. 14, n. 2, p. 11-39, 2007. Disponível em: http://philpapers.org/rec/RUIAED. Acesso em: 23 mar. 2011.

SAHD, F. B. Sionismo, modernidade e barbárie: vida e morte na Faixa de Gaza. Curitiba: Editora Graciosa, 2012.

SANTOS, B. de S.; MENESES, M. P. (org.). Introdução. In: SANTOS, B. de S.; MENESES, M. P. Epistemologias do Sul. São Paulo: Cortez, 2010.SASSEN, S. Expulsões. Brutalidade e complexidade na economia global. Rio de Janeiro; São Paulo: Paz e Terra, 2016.SERRANO, A. S. Revolución de los derechos humanos de los pueblos o carta socialdemócrata a Santa Claus? In: MARTínEZ, A. et al. Teoria crítica dos direitos humanos no século XXI. Porto Alegre: EDIPUCRS, 2008.

SILVA, J. A. e. As Nações Unidas e a luta internacional contra o racismo. 2. ed. Brasília: Fundação Alexandre de Gusmão, 2011.

TODOROV, T. O medo dos bárbaros: para além do choque das civilizações. Petrópolis: Editora Vozes, 2010.

UNHCR. United Nations High Commissioner for Refugees. Figures at a glance. Dados de 19 de junho de 2019. Disponível em: https://www.unhcr.org/figures-at-a-glance.html. Acesso em: 30 jul. 2019.

WALLERSTEIN, I. O universalismo europeu: a retórica do poder. São Paulo: Boitempo, 2007. 